\title{
Implementation of a Coastal Management Model at Kinvara Bay in the North Atlantic Ocean
}

\author{
Catalin Anton ${ }^{1}$, Carmen Gasparotti ${ }^{1}$, Iulia Anton ${ }^{2}\left(\mathbb{D}\right.$ and Eugen Rusu ${ }^{3, *(1)}$ \\ 1 Department of Naval Architecture, Faculty of Naval Architecture, Dunarea de Jos University of Galati, \\ 47 Domneasca Street, 800008 Galati, Romania; catanton@gmail.com (C.A.); \\ Carmen.Gasparotti@ugal.ro (C.G.) \\ 2 Department of Civil Engineering, School of Engineering \& Informatics, National University of Ireland \\ Galway, University Road, Galway H91HX31, Ireland; iulia.anton@nuigalway.ie \\ 3 Department of Mechanical Engineering, Faculty of Engineering, Dunarea de Jos University of Galati, \\ 47 Domneasca Street, 800008 Galati, Romania \\ * Correspondence: eugen.rusu@ugal.ro
}

Received: 17 December 2019; Accepted: 19 January 2020; Published: 23 January 2020

\begin{abstract}
Applying a management model to coastal areas is always a challenge because of the multiple scenarios from which they can be addressed. The coastal zone represents a dynamic area, which can be analyzed using physical processes. However, it can also be analyzed from the perspective of land-sea interaction or the socio-economic activities that take place in the area. Last but not least, the coastal area holds great significance for biodiversity, as well as for the communities that live there, their traditions and customs, and their cultural heritage, especially in the context of climate change and sea-level rise. In this context, the present paper aims to analyze the social and economic aspects of environmental protection issues and how these factors, identified by a series of indicators, can coexist together. The target area is Kinvara Bay, which is located south of the Atlantic's Galway Bay, in the western part of Ireland.
\end{abstract}

Keywords: coastal zone; management model; Kinvara Bay; Atlantic Ocean; land-sea interaction

\section{Introduction}

The phenomenon of globalization involves interaction between communities in different locations, which causes physical boundaries separating states to diminish in importance when it comes to daily activities. The importance and value of the products and services that a community produces, the resources it allocates, and the sustainable way in which it develops its infrastructure and economy while preserving its cultural traditions represent its competitive value. Coastal areas are spaces in which activities are carried out at a much more dynamic pace, since competition between communities is much stronger. Several years ago, the environmental protection component became highly valued, representing a secondary objective in the management of most companies. Today, concepts such as transparency and responsibility, environmental health, and environmental protection are starting points in most analyses of macroeconomic and social strategies. In this sense, this stage of strategic analysis becomes the first basic step of strategic management when considering both a company and a community [1].

The present paper refers to a multicriteria analysis of the coastal area of Kinvara Bay, located in the western part of the Republic of Ireland, and includes many factors related to the respective area, starting with economic, social, and environmental protection activities. A series of indicators was developed for each of these activities [2].

In this case, the development of a management model aims to highlight competitive advantages and, at the same time, identify the pressures and threats that some indicators exert on others. The model 
is based on the PESTEL analysis (Political, Economic, Socio-cultural, Technological, Environmental, and Legal) [3]. A PESTEL analysis has various notions in the scientific literature, starting with PEST (Political, Economic, Socio-cultural, and Technological) and STEPE (Socio-cultural, Technological, Economic, Political, and Environmental) [4]. Initially, this analysis was conceived by Aguilar as an analysis of political, social, technical, and economic factors (ETPS); it was then re-thought by Arnold Brown for the Life Insurance Institute (as STEP), but analysis of environmental changes was added later. After 1980, a legal dimension was introduced.

For the analysis of Kinvara Bay, we considered three of the six factors of PESTEL, forgoing the political, technological, and legal factors.

Most of the time, political factors are given the most importance. Government or regional policy decisions can affect economic and social development and may affect the environment or the emergence and implementation of new technologies. The political factor can, at the same time, be a progress factor and also a risk factor that could lead to major vulnerability. In general, there are several indicators analyzed when calculating the political factor. They refer to bureaucracy, level of corruption, freedom of the press, pluripartidism, free elections, and so forth. The reports analyzed by the authors, which are from the United Nations, World Bank, European Central Bank, Unicef, and the European Union, contain analyses of the political factor and situate the Republic of Ireland as a state that rigorously fulfills the criteria for political efficiency and the rule of law. The authors also analyzed the legislative provisions in the field of education, anti-trust, labor, discrimination, data protection, environmental protection and pollution, health and safety, competition regulation, fiscal policy (tax rates and incentives), intellectual property (copyright, patents), consumer protection, and e-commerce. First of all, it can be noticed that the Republic of Ireland has largely implemented the recommended directives and regulations approved by the European Parliament. The analyzed reports presented above did not reveal any legislative deficiency in the analyzed areas.

In the coastal area of Kinvara Bay, technological factors were introduced within the economic factor as indicators of industry, economic performance, and energy.

This strategic analysis of Kinvara Bay aims to identify the environment in which activities existing in the area are carried out, including the pressures that arise as a result of the action of natural or anthropic factors, which may weaken the area analyzed in the short, medium, and long term. Clearly, this analysis is a precondition, but it still presents some limitations in terms of measurement and evaluation. In this paper, we did not intend to carry out a quantitative measurement of the analyzed factors, taking into account the values generated by the analyzed activities (such as air quality analysis through the analysis of $\mathrm{CO}, \mathrm{SO}_{2}, \mathrm{O}_{3}, \mathrm{NO}_{x}, \mathrm{PM}_{2.5}$, or $\mathrm{PM}_{10}$ emission values), but we did want to show the interactions between these activities that generate pressure, resulting in the vulnerability of some activities. We will take into account a statistical sampling technique in order to obtain a probabilistic approximation of the solution to a model, as in the case of the Monte Carlo simulation [5-7]. This simulation combines probability distributions based on existing relationships in models by testing multiple combinations of input variables and storing results for display.

\section{Materials and Methods}

The Republic of Ireland has a local administration system, which includes county councils and city councils. Since 2014, the county and city councils have been replaced by a system of municipal districts, which integrate the governance of cities and counties. At the county or city level, there are 31 city and county councils with integrated municipal districts. They are the main providers of local government services throughout the country. Kinvara is part of Galway County in the west of the Republic of Ireland. Kinvara Community Council was formed in 1990. 
Kinvara Bay is part of the Galway Bay Southeast Catchment, as described in a report by the Irish Environmental Protection Agency (EPA; 2018). The global coverage basin covers the drained surface of all streams entering Galway Bay between Black Head and Renmore Point. As such, the basin has a total area of $1270 \mathrm{~km}^{2}$, with a population of approx. 74,400 and a population density of 59 persons per $\mathrm{km}^{2}$ (Figure 1). The main urban centers, apart from Galway, are Athenry, Loughrea, Gort, and Oranmore. The river basin comprises 9 sub-basins, with 33 river water bodies, 6 lakes, 20 transitions, 9 coastal water bodies, and 17 groundwater bodies. There are no highly modified or artificial water bodies in the basin [8].

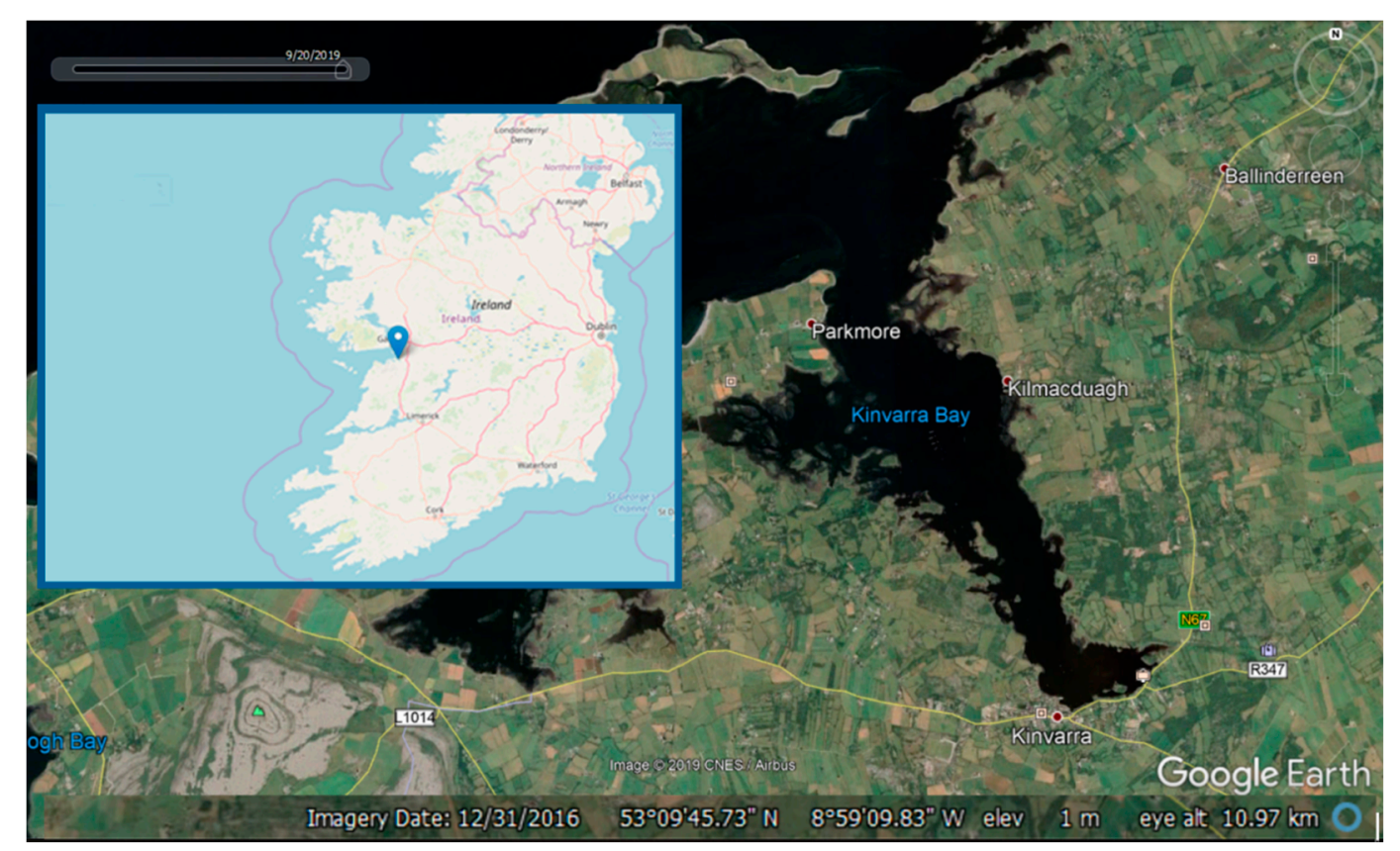

Figure 1. Kinvara Bay (adapted from Google Earth and Epsg.io source).

In the basin, there are 15 group water schemes, 7 public deliveries, and another 3 schemes, with a total of 44 extractions from 8 underground water bodies, one from Lough Rea, and one from the Cannahowna River (Figure 2). Freshwater drainage water and three seawater baths are designated in the basin, with a single Ballyloughane beach, which has failed to achieve good water quality results. The profile of the bathing water indicates that significant pressure comes from the urban sewers from the east of Galway. There are three designated areas of basin shells. There are also 25 special conservation areas (SACs), some of which are habitats with species that are dependent on water. Therefore, 18 surface water bodies, 12 transient water bodies, and 2 groundwater bodies were prioritized for action. Although there are seven special protected areas (SPAs) in the river basin, there are no specific conditions to support the quality of water required for the site-specific conservation objectives. 


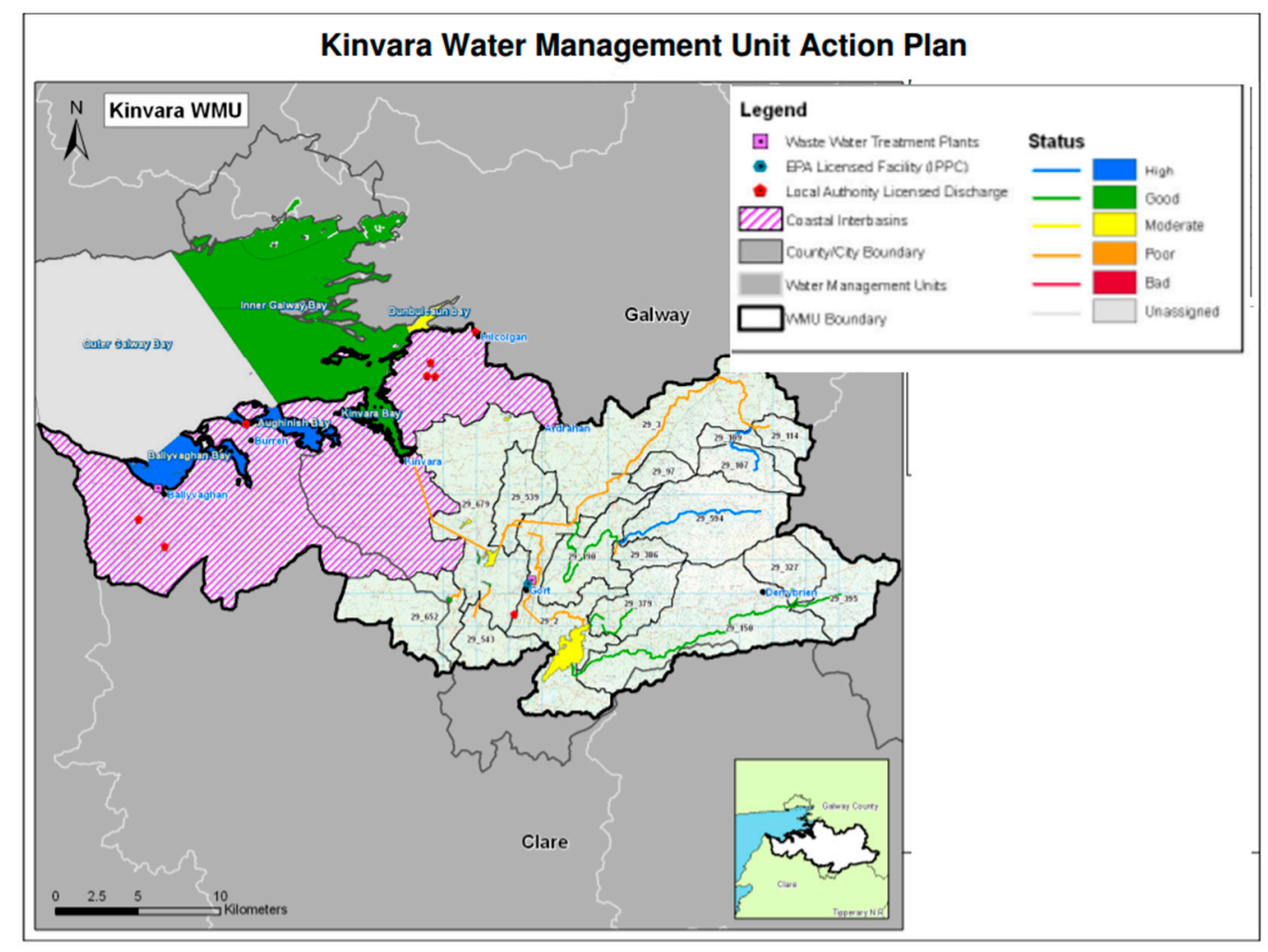

Figure 2. Kinvara catchment area (adapted from http://www.wfdireland.ie source).

The multicriteria analysis model considered for the coastal area of Kinvara Bay was based on the PASTEL type of analysis. This model identified the relevant forces that put pressure on the analyzed coastal and marine area. This model can be implemented on any coastal area, starting by clearly identifying the activities and the pressure in the respective area, and taking also into account that each coastal area has its specific features [9-12].

The model created must be validated over time, so it is necessary to periodically perform multicriteria analyses to identify possible changes in the components of the analyzed factors [13]. The more detailed the analysis, and the shorter the intervals, the better becomes the framework that can be created for identifying and mitigating potential vulnerabilities given by the overlapping pressures of some factors [14].

Given the above, for the analysis of Kinvara Bay, we considered three of the six factors in the PESTEL analysis, giving up the political, technological, and legal factors. The Republic of Ireland, being a country of the European Union, has a general legislative framework in line with EU standards, which are some of the most restrictive in the world in terms of environmental protection but also respect human fundamental freedoms. Also, politically, taking into account the fact that Ireland is part of the European Union, it was assumed that the country successfully met the political standards accepted by the community group. Regarding the technological indicators, which mainly concern industrial activities, in considering the analyzed area, where there are very few industrial activities and are limited to the meat processing industry, we considered them not very relevant in the present analysis. However, some indicators, especially those of a legislative nature, can be found included in the social indicators (the indicator of safety and security that concerns the existing legislative framework) [15-18]. As for the other factors, they are described in the following. 
Economic factor: Indicators regarding the activities in the area as well as their impact on other economic, social, and environmental activities were identified [19]. Thus, agriculture and, in particular, animal husbandry represents the main economic activity of the analyzed area. Another potential economic activity is aquaculture, especially oyster crops. Tourism is also an important economic activity in the area. Car traffic and economic performance given by access to broadband internet were also analyzed.

Social factor: This considered the social environment and identified the trends existing in the analyzed area. Six indicators were established to analyze this factor, namely urban agglomeration, active labor force, crime, education, health, and cultural heritage [20].

Environmental factor: This factor referred to the influence that other factors had on the environment and the impact of ecological aspects. The environmental factor includes relevant indicators regarding the components of air, water, soil, and waste.

In Figure 3, the steps required to perform a PESTEL type of analysis are presented.

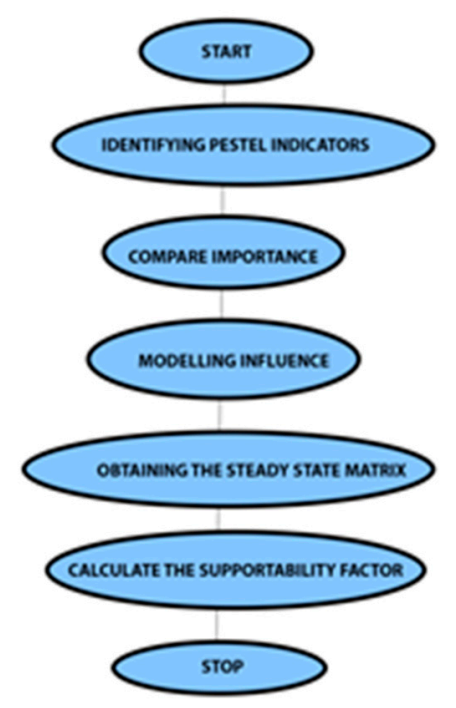

Figure 3. The framework for conducting a PESTEL (Political, Economic, Socio-cultural, Technological, Environmental, and + Legal) analysis (author).

Nomination of the indicators of the three proposed factors alone is not enough to carry out an efficient analysis that will be the basis of a sustainable model for the coastal zone. The interaction between the proposed indicators and how some of the indicators place less or greater pressure on others must be identified (Figure 4) [21,22]. For example, in the breeding activity of animals, the nutrients produced affect the groundwater, which leads to poor water quality. The fact that these waters of not very good quality reach the Bay of Kinvara affects the economic activity of raising oysters, which means that the economic activity of raising animals puts pressure on the economic activity of raising oysters. 


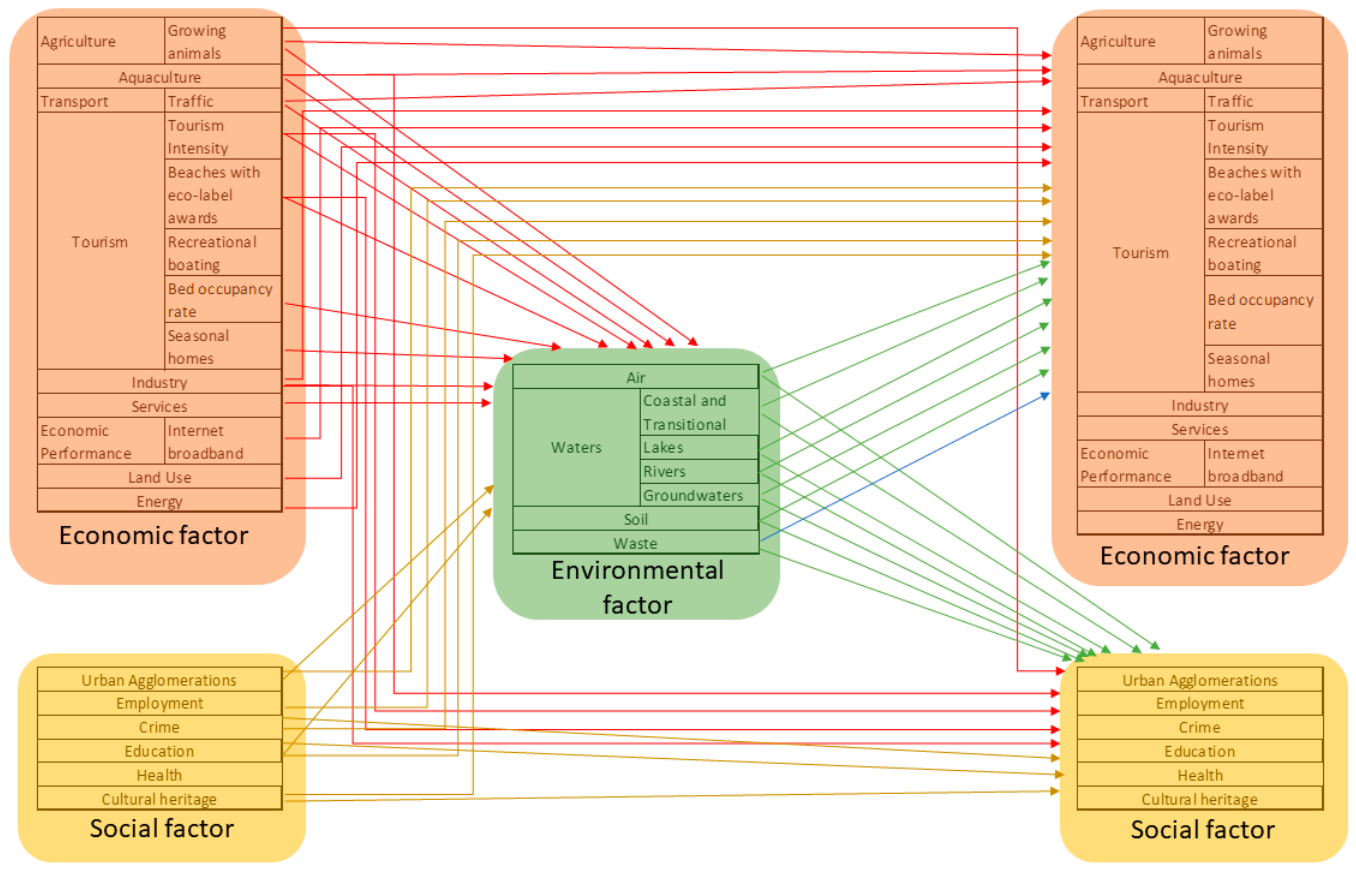

Figure 4. Interaction between the indicators proposed for analysis (authors).

To quantify the interaction between these activities, we used the notion of a supportability factor. This instrument represents the threshold at which one of the activities can exist without causing the other activity to disappear. For non-interacting activities, the stability factor was set to zero. For activities that harmed each other, the supportability factor was negative, on a scale from zero to minus five, depending on the greater or lesser impact between activities. Likewise, if an activity had a positive effect on the other, the supportability factor was also positive, on a scale from zero to five [23]. The impact was established based on existing data from official sources. For example, the pressure exerted by agricultural activities, namely raising animals and its impact on groundwater, was based on the report of the Environmental Protection Agency regarding water from the Gort-Kinvara river basin (Figure 5). This report clearly showed that the main sources of pressure were from agricultural activities and also domestic activities, more precisely by the septic tanks in the households. In this case, the supportability factor was negative because the quality of the groundwater was affected by the indicator established for the economic factor-agriculture-and since the effect was very high, the supportability factor reached the maximum limit. The allocation of these values was empirical, based on data collected in the area and also on similar studies conducted by the Marine Institute and the National University of Ireland, Galway.

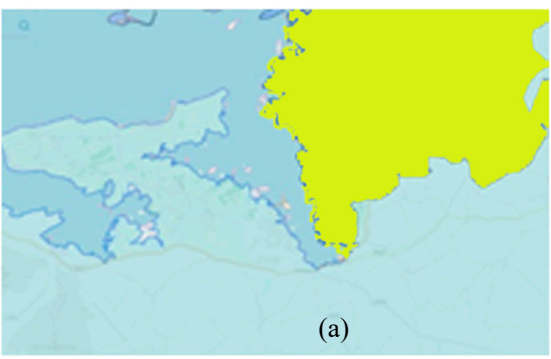

$\square$ Groundwater agriculture pressure

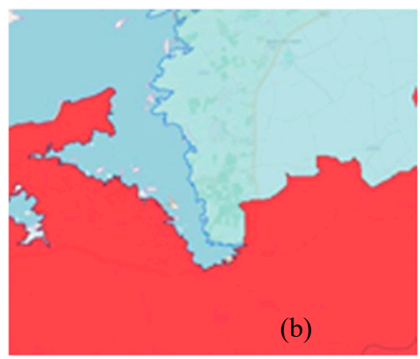

$\square$ Groundwater anthropogentic pressure

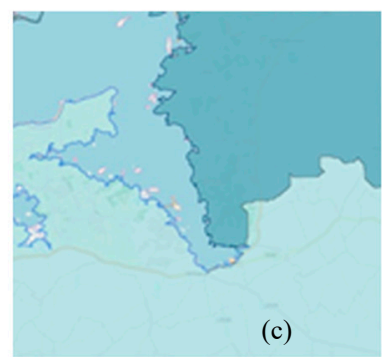

$\square$ Groundwater domestic waste waters pressure

Figure 5. Some examples of groundwater pressures: (a) pressure from agriculture sources; (b) pressure from anthropogenic sources; (c) pressure from domestic wastewater sources (adapted from EPA). 


\section{Results}

The interaction between the activities that took place in the coastal area was defined with the generic term land-sea interaction, used in the context of marine planning and management in the coastal areas. As we already mentioned, the interaction was between economic, social, and environmental factors. As an example, this type of interaction may include, but is not limited to, the flow of contaminants from a terrestrial agricultural surface to a freshwater body, which is in contact with the coastal waters. This represents an economic-environmental interaction, but it may also be the type of bathing water that affects coastal tourism, which represents an environmental-economic interaction. On the one hand, it is necessary to know that the same factor can exert an impact on other factors but, at the same time, can receive the impact of other factors.

There was a close connection between most of the activities that were analyzed within integrated coastal zone management. Consistency and integration between marine and terrestrial spatial planning are important and should be achieved through consistent policies, plans, and decisions. Some uses, especially in the field (e.g., beach tourism, waterfront, ports), also extended their scope to the sea. These interactions should be identified and mapped to assess their cumulative impact and potential conflicts and synergies.

In the table below, we established the interaction mode between the activities of the three analyzed factors, namely the economic factor, the social factor, and the environmental factor. This was also outlined in Table 1. In this table, the factors that were the source of interaction were depicted in the rows, and the factors that were targeted by the interaction were presented in the columns. As it can be seen, most pressures were created by economic factors, and the environmental factors absorbed most pressures.

Table 1. Interaction mode between economic, environmental, and social factors (authors).

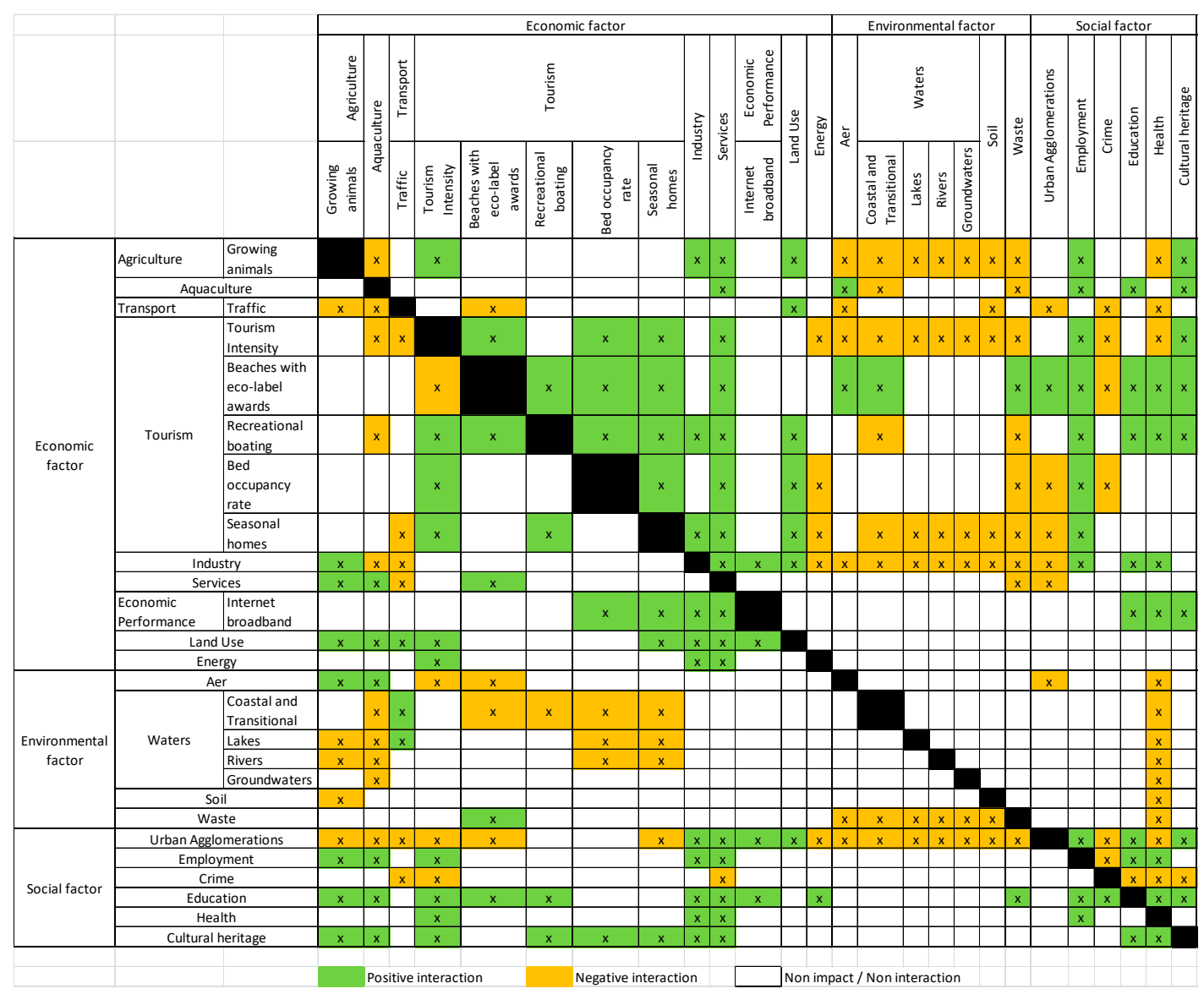


Regarding the valorization of factors in the table below, impacts between indicators can be ascertained following the interaction between the proposed factors (Table 2). The authors considered that the theory of integrated coastal zone management should be applied in this situation, in which the factors interact, sometimes generating conflicts, between existing activities.

In determining the valuation, it was established that the activities that did not affect each other had zero value. The pressures exerted by one activity on another had a positive or negative impact, and the value was between minus five to five depending on the pressure exerted. A value of -5 represents the maximum point at which an activity can withstand the pressures of another activity. The evaluation was based on data obtained from various sources. In the discussion chapter, we explain how the evaluation was done and also the origins of the sources used.

Table 2. Valuation impact of activities (authors).

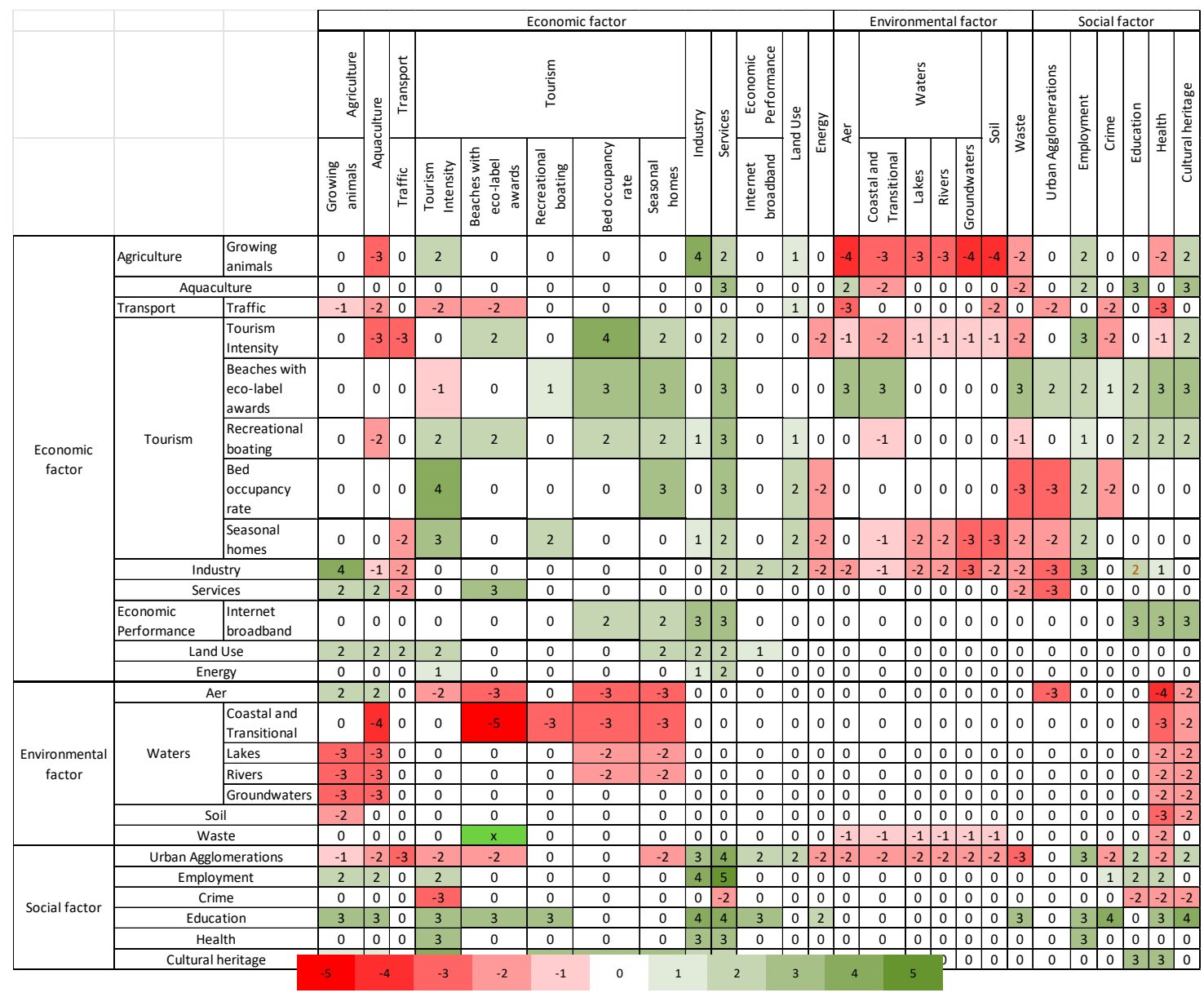

Graphically, Figure 6 shows the impact on each factor. 


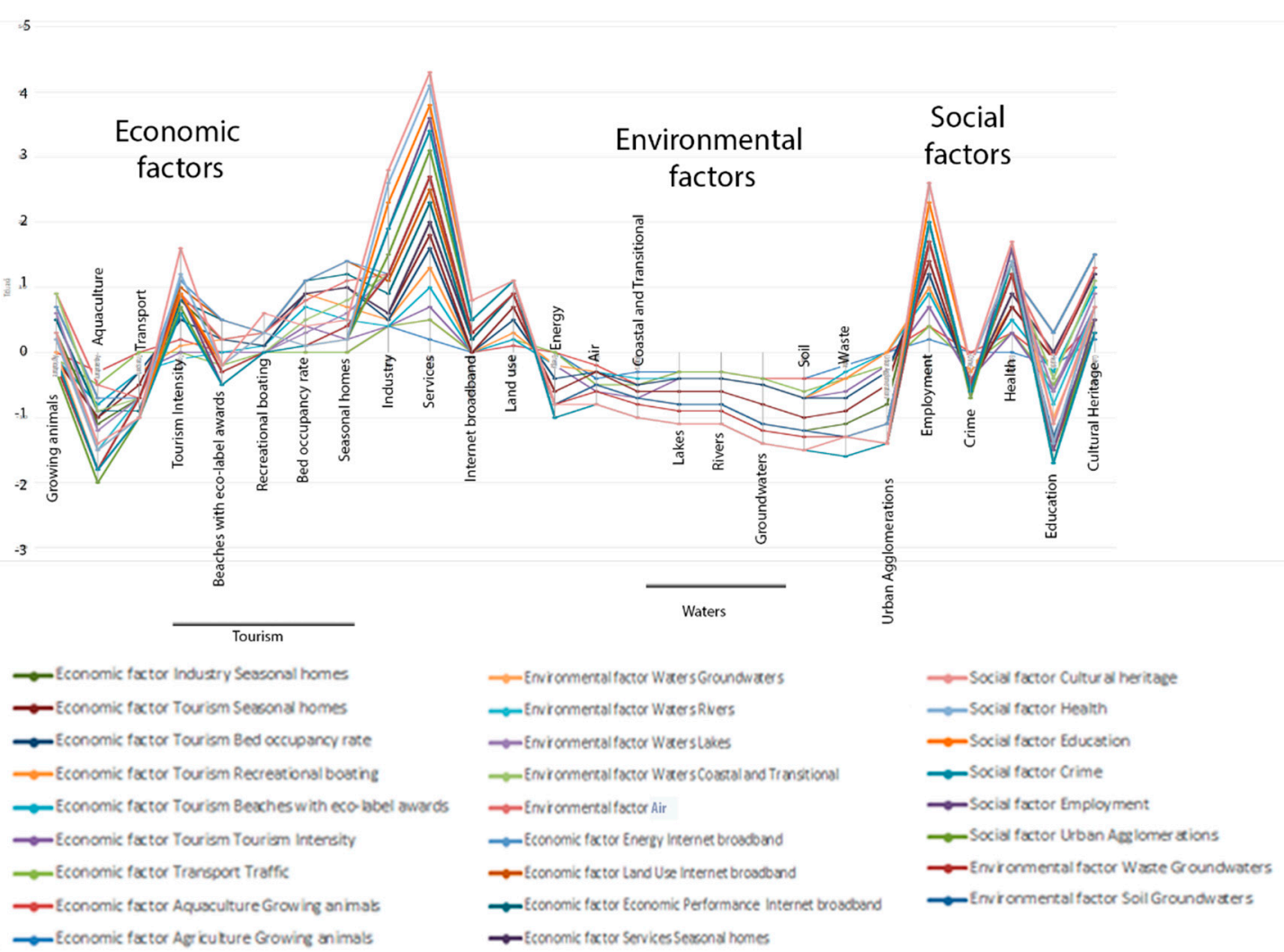

Figure 6. Graphic representation of the impact between the activities in the coastal area (author).

Generally, when indicators are based on data coming from different fields of analysis, their aggregation is done using weights corresponding to the calculation norms and the existing standards in the respective field.

In the case of insufficient or inconclusive data, aggregations should be treated as approximations to unknown totals or average values.

The aggregation rules are intended to produce estimates for a constant set of data from one period to another and for all indicators.

In the analyzed case, we used results of the median report coming from the sum of the values of the interactions exercised at the level of an analyzed activity (Table 3 ) and of the average values for the factors (economic $=0.139053254$, social $=-0.505494505$ and environmental $=0.487179487$ ). The corresponding graphical representations can be seen in Figures 7 and 8 . 
Table 3. Average values of economic, social, and environmental indicators (author).

\begin{tabular}{|c|c|c|c|}
\hline \multirow{13}{*}{ Economic Factor } & Agriculture & Growing Animals & -0.57692 \\
\hline & \multicolumn{2}{|c|}{ Aquaculture } & 0.346154 \\
\hline & Transport & Traffic & -0.69231 \\
\hline & \multirow{5}{*}{ Tourism } & Tourism Intensity & -0.19231 \\
\hline & & Beaches with eco-label Awards & 1.192308 \\
\hline & & Recreational Boating & 0.615385 \\
\hline & & Bed occupancy rate & 0.153846 \\
\hline & & Seasonal Homes & -0.26923 \\
\hline & \multicolumn{2}{|c|}{ Industry } & -0.23077 \\
\hline & \multicolumn{2}{|c|}{ Services } & 0 \\
\hline & Economic Performance & Internet Broadband & 0.730769 \\
\hline & \multicolumn{2}{|c|}{ Land Use } & 0.576923 \\
\hline & \multicolumn{2}{|c|}{ Energy } & 0.153846 \\
\hline \multirow{7}{*}{ Environmental Factor } & \multicolumn{2}{|c|}{ Air } & -0.61538 \\
\hline & \multirow{4}{*}{ Waters } & Coastal and Transitional & -0.88462 \\
\hline & & Lakes & -0.53846 \\
\hline & & Rivers & -0.53846 \\
\hline & & Groundwaters & -0.38462 \\
\hline & & Soil & -0.26923 \\
\hline & & Taste & -0.30769 \\
\hline \multirow{6}{*}{ Social Factor } & \multicolumn{2}{|c|}{ Urban Agglomerations } & -0.57692 \\
\hline & \multicolumn{2}{|c|}{ Employment } & 0.769231 \\
\hline & \multicolumn{2}{|c|}{ Crime } & -0.42308 \\
\hline & \multicolumn{2}{|c|}{ Education } & 1.730769 \\
\hline & \multicolumn{2}{|c|}{ Health } & 0.461538 \\
\hline & \multicolumn{2}{|c|}{ Cultural Heritage } & 0.961538 \\
\hline
\end{tabular}

Chart of average values

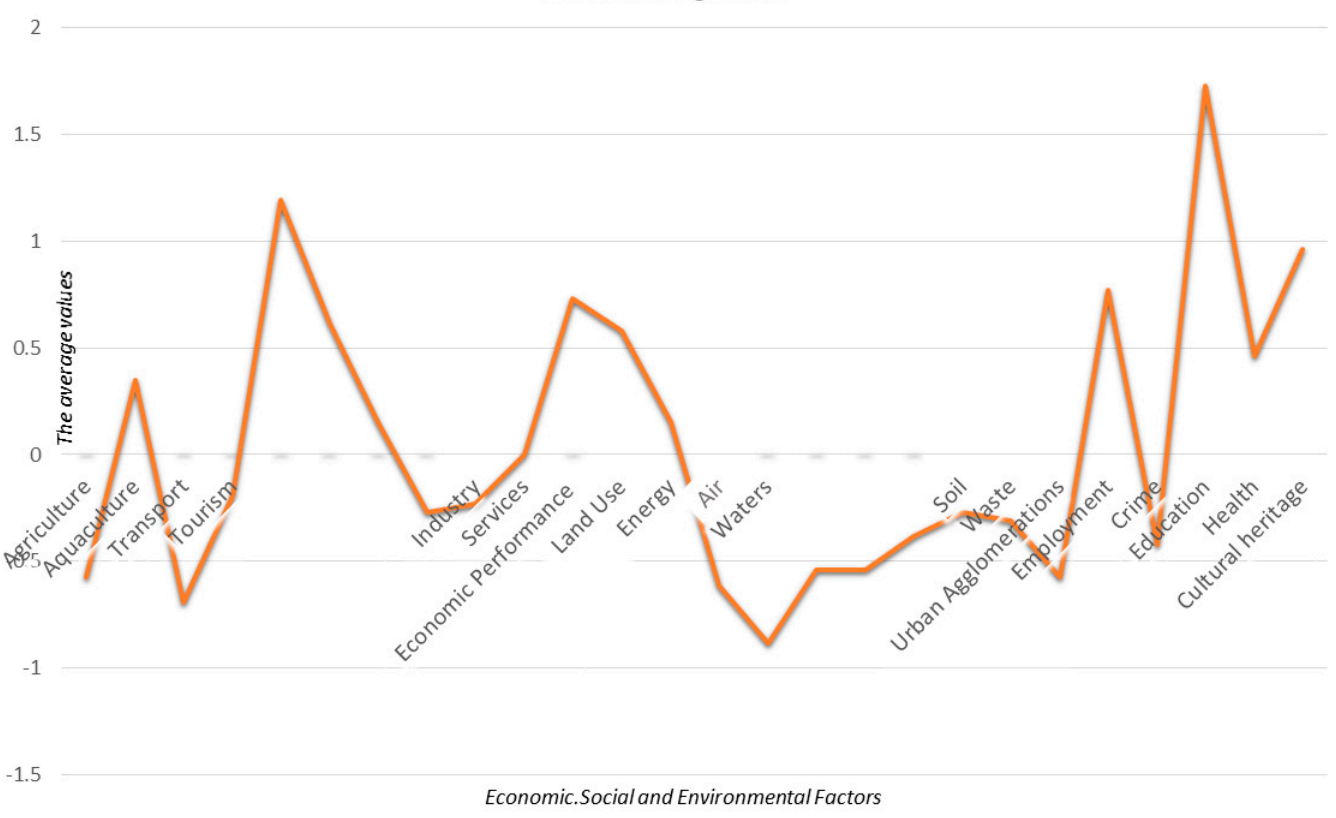

Figure 7. Average values of economic, social, and environmental indicators (author). 


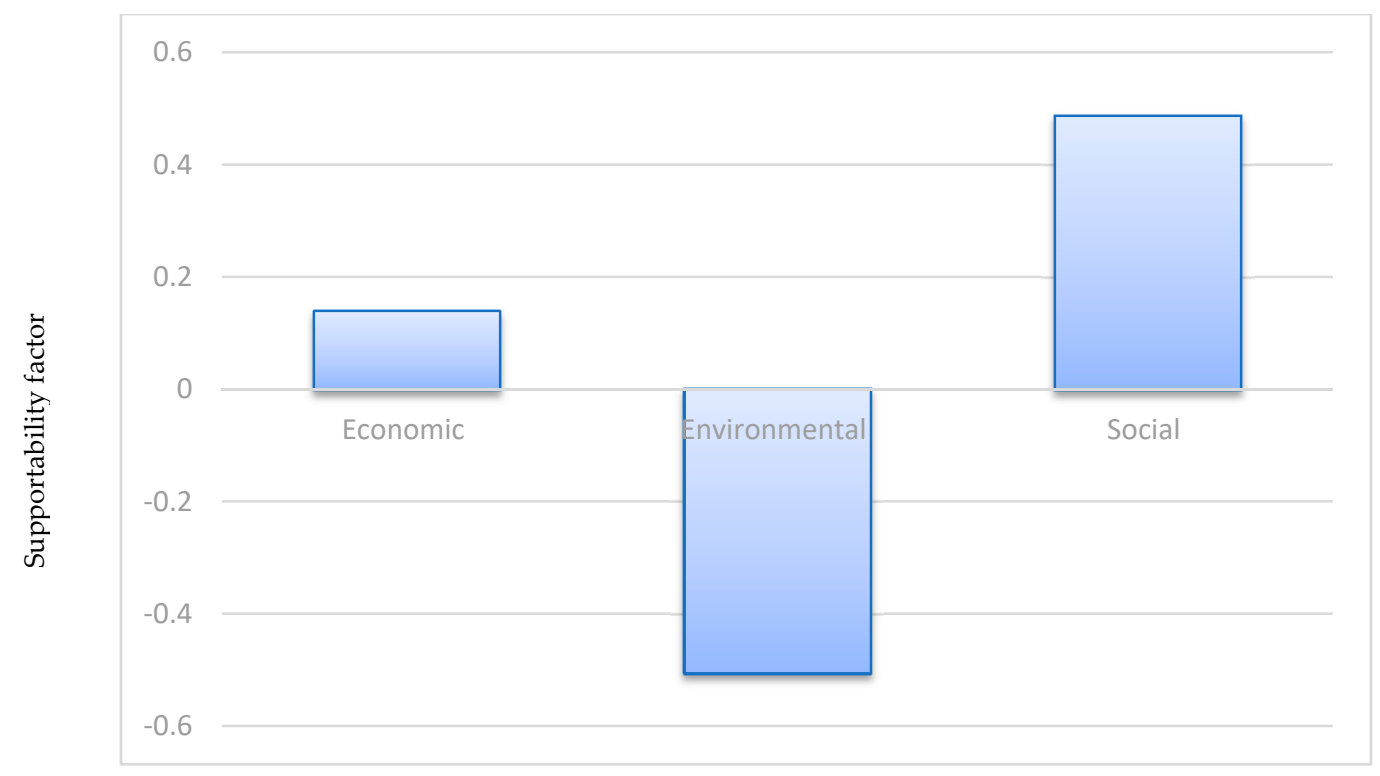

Figure 8. Average value for each factor (author).

\section{Discussion}

The Organization for Economic Cooperation and Development has stated that the overall objective of integrated coastal zone management is to maximize the benefits offered by the coastal area and to minimize the conflicts and harmful effects of some activities on others. Coastal management focuses on the interactions between activities in the coastal area and activities in other regions. The present work aimed to identify an integrated management model that, on the one hand, can be applied to the particularities of the Kinvara Bay area and, on the other hand, can be applied to other situations. Analyses of each of these situations started from the particularities of the analyzed area, using a matrix of economic, social, and environmental factors, to which other factors of the PESTEL analysis can be added (i.e., political, legislative, and technological factors).

Validation over time is absolutely necessary for the new model created. This should be done periodically through a multicriteria analysis to identify changes in the components of the analyzed factors. Within the analysis, local, regional, national, and international objectives should be integrated. Using a holistic perspective, the model avoids traditional sectorial interconnections between the coastal systems and uses management approaches.

The interrelation and interaction between the indicators of the factors proposed for this analysis are very important because, in some cases, the interaction can have a positive effect, and in other situations, the effect may be predominantly negative or does not exist. That is why it is very important, especially in the situation of a negative effect, that we quantify what the threshold is where the negative effect becomes a vulnerability that can lead to a disaster [24]. In previously published works that were part of the preparation of the doctoral thesis of the first author, we developed an instrument that we called the supportability factor.

This tool is useful to determine the degree of supportability of one indicator with another. In general, an ideal situation is a constant situation in which the analyzed indicators do not affect, or positively affect, each other. However, in the theory of coastal zone integrated management, there are existing conflicts between activities. It is natural to have such conflicts; for example, in coastal areas there are tourist activities but also protected areas that require protection measures against human activities [25]. Therefore, by establishing a supportability factor, we will see how much it can withstand one of the existing activities and the pressure of the others.

In determining the supportability factor, it was established that if the activities did not affect each other, they would have a zero value. Also, the pressures they exerted had a positive or negative impact, 
and the value will be between minus five to five. If the impact of one activity on the other is negative, that means a pressure is affecting one activity. A value of -5 represents the maximum point at which one activity can withstand the pressures of the other activities. Above this value, the activity can no longer exist in the respective area [26].

The allocation of the value scale between -5 and 5 is not accidental; it is based primarily on the theory of risk analysis. A risk assessment consists, in our case, in studying the probability that the activity will reach a satisfactory performance. In this context, the probability must be interpreted as an index in which a value of 5 represents complete certainty that a prediction will be confirmed, a value of -5 represents the certainty that a prediction will not be confirmed, and intermediate values for any situation between the two extremes can be identified [27]. The instrument of probability was used as an evaluation tool. The values of this scale can be generated by the experience of specialists in the field at the local or regional level. Probability thresholds reflect the perception of decision-makers about the uncertainty with which the identified risks may be associated. In some of the analyzed activities, a qualitative evaluation is required, while in others, a quantitative evaluation is required.

This theory was initiated by a Monte Carlo analysis, developed in the 1940s, and it is a computerized method that uses statistical sampling techniques to obtain a probabilistic approximation to the solution of a model. In this context, the simulation consists of the process of approximating model results by repetitive random applications of the model algorithm.

The Monte Carlo simulation combines probability distributions according to the relationships existing in the models by testing several combinations of input variables and storing the results for display. The relevance of this method is that the results are often graphs of probability distributions or cumulative probability distributions of output variables, such as the total cost or completion dates. These results allow the complete and objective measurement of the different risks [28]. In addition to multicriteria analysis (MCA), several statistical techniques can be used to evaluate project risks, such as PERT (repeated program evaluation technique), sensitivity analysis, and decision tree analysis.

Regarding the sources used, these were mainly based on official reports or analytical studies in the area. Data on the quality of environmental factors were obtained in particular from the Environmental Protection Agency of Ireland (EPA). The report on the Kinvara-Gort River Basin Management Plan provides extensive data of existing pressures on ground and surface waters as well as transitional and marine waters in Kinvara Bay.

Also, the online catchments.ie database provided current data on the factors analyzed in this paper. The Marine Institute in Galway has also developed a comprehensive study of socio-economic pressures on oyster cultivation in the Kinvara Bay area. Last but not least, the Galway County Council has developed a series of studies and strategies for the socio-economic development of the region, such as the Galway County Development Plan 2015-2021, which provided the authors with useful information for this work [29-31].

\section{Conclusions}

This study is part of larger research on the impact of coastal activities under the conditions of sustainable development. The application of the PESTEL analysis aims to determine the interactions between the environmental activities and the social and economic activities, as in our case, but also the technological, political, and legislative activities that are exercised over a coastal area.

Strategic analysis on Kinvara Bay has identified an environment in which the existing activities, as well as the pressures that arise as a result of the natural or anthropic factors of these activities, may weaken the area analyzed in the short, medium, and long term. The multicriteria analysis model used in the coastal area of Kinvara Bay identified the relevant forces that put pressure on this coastal and marine area. Improving the quality of the environmental factors, especially the quality of the groundwater, is a clear objective for authorities in the medium and long term. Also, the diversification of economic activities, and especially the increase in the share of tourism in the analyzed area, will give an aspect of sustainability. However, in order to develop this area, degradation of coastal ecosystems must be 
mitigated, providing a common framework for managing multisectoral activities and maintaining options for future coastal resource uses. Applying this model will create a multisectoral perspective and approach that considers all sectoral and stakeholder interests and addresses economic, social, environmental, and ecological issues.

Quantifying these activities with the help of the supportability factor shows us even more clearly how high the pressure is on one or another activity and where it comes from.

This allows an integrated and multifactorial assessment of a situation, representing a tool to support decision-makers at the local, regional, or national level. Of course, the model can be developed by introducing more indicators or by directing the indicators to a certain aspect that is to be analyzed. Also, when calculating the supportability factor, calculation thresholds can be established based on statistical data, or data collected from the field, regarding the interaction between them.

It should also be specified that, for a model to be as viable as possible, the quality of the data collected, as well as the actuality of these data, is very important. The use of data from different periods can lead to the development of different models. Also, calibration of the model can be done over time by constantly updating the entered data.

However, it is not always possible to accurately quantify all proposed indicators. Often, they have certain ambiguity in their structure. Thus, this multifactorial analysis will be further developed in our future research, considering also unpleasant experiences in measuring these indicators.

Author Contributions: The first and the third authors (C.A. and I.A.) had the idea of developing the work, gathered the data and designed the figures and tables. The methodologies and approaches to be considered have been discussed with the second author (C.G.). The work supervision was provided by E.R. who was also the corresponding author. All authors have read and agreed to the published version of the manuscript.

Funding: This research was funded by the project "Excellence, performance and competitiveness in the Research, Development and Innovation activities at "Dunarea de Jos" University of Galati", acronym "EXPERT", financed by the Romanian Ministry of Research and Innovation in the framework of Programme 1-Development of the national research and development system, Sub-programme 1.2. Institutional Performance. Projects for financing excellence in Research, Development and Innovation, Contract no. 14PFE/17.10.2018.

Acknowledgments: For the first author, this work is supported by the project ANTREPRENORDOC, in the framework of Human Resources Development Operational Programme 2014-2020, financed from the European Social Fund under the contract number 36355/23.05.2019 HRD OP /380/6/13 - SMIS Code: 123847. For the third author, this work is supported by Postdoctoral Research role of the project Wave Resource Characterisation at the Galway Bay Marine and Renewable Test Site implemented by Nationl University of Ireland, Galway financed from the Marine Research Programme 2014-2020

Conflicts of Interest: The authors declare no conflicts of interest.

\section{References}

1. Anton, C.; Gasparotti, C.; Anton, I.A.; Rusu, E. Analysis of the mamaia bay shoreline retreat with hard and soft protection works. J. Mar. Sci. 2019, 1, 7-17. [CrossRef]

2. Kindermann, G.; Anton, C.; Pender, K.; Cave, R. EU life feasability study-Flag funded Cuanbao project. 2019; unpublished work.

3. Yüksel, I. Developing a multi-criteria decision making model for PESTEL analysis. Int. J. Bus. Manag. 2012, 7, 24. [CrossRef]

4. Richardson, J.V., Jr. The library and information economy in Turkmenistan. IFLA J. 2006, 32, 131-139. [CrossRef]

5. Diaconu, S.; Rusu, E. The environmental impact of a wave dragon array operating in the Black Sea. Sci. World J. 2013. [CrossRef] [PubMed]

6. Panaitescu, F.-V.; Panaitescu, M.; Anton, I.-A.; Anton, C.; Turof, M. New solutions to protect the Romanian coastline. In Proceedings of the SPIE-The International Society for Optical Engineering, Bellingham, WA, USA, 24-26 September 2018; p. 10977.

7. Rusu, E.; Soares, C.G. Wave energy assessments in the coastal environment of Portugal continental. In Proceedings of the 27th International Conference on Offshore Mechanics and Arctic Engineering-OMAE, Berlin, Germany, 9-13 June 2008; Volume 6, pp. 761-772. 
8. Marine Institute. Characterisation Report Number V-Clarinbridge Kinvarra Bay Shellfish Area County Galway. Available online: https://www.housing.gov.ie/sites/default/files/publications/files/filedownload220 59en.pdf (accessed on 14 December 2019).

9. Anton, I.A.; Rusu, L.; Anton, C. Nearshore wave dynamics at Mangalia beach simulated by spectral models. J. Mar. Sci. Eng. 2019, 7, 206. [CrossRef]

10. Rusu, E.; Măcuţă, S. Numerical modelling of longshore currents in marine environment. Environ. Eng. Manag. J. 2009, 8, 147-151. [CrossRef]

11. Rusu, E.; Conley, D.; Ferreira-Coelho, E. A hybrid framework for predicting waves and longshore currents. J. Mar. Syst. 2008, 69, 59-73. [CrossRef]

12. Ivan, A.; Gasparotti, C.; Rusu, E. Influence of the interactions between waves and currents on the navigation at the entrance of the Danube Delta. J. Environ. Prot. Ecol. 2012, 13, 1673-1682.

13. Anton, C.; Gasparotti, C.; Rusu, E. Identification of the economic pressure on environmental factors in the Romanian coastal zone-case study Eforie. In Proceedings of the 18th International Multidisciplinary Scientific GeoConference Surveying Geology and Mining Ecology Management (SGEM), Albena, Bulgaria, 2-8 July 2018; p. 461.

14. Anton, C.; Gasparotti, C.; Rusu, E.; Anton, I.A. Approach to the analysis and evaluation of the strategic intervention options in the Romanian coastal zone taking into account economic, social and environmental factors. In Proceedings of the 18th International Multidisciplinary Scientific GeoConference Surveying Geology and Mining Ecology Management (SGEM), Albena, Bulgaria, 2-8 July 2018; p. 67.

15. Cheng, E.W.L.; Li, H. Application of ANP in process models: An example of strategic partnering. Build. Environ. 2007, 42, 278-287. [CrossRef]

16. Dare, C. The UK tour-operating industry: A competitive analysis. J. Vacat. Mark. 2006, 6, 357-367.

17. Saaty, T.L.; Takizawa, M. Dependence and independence: From linear hierarchies to nonlinear networks. Eur. J. Oper. Res. 1986, 26, 229-237. [CrossRef]

18. Shilei, L.; Yong, W. Target-oriented obstacle analysis by PESTEL modeling of energy efficiency retrofit for existing residential buildings in China's northern heating region. Energy Policy 2009, 37, 2098-2101. [CrossRef]

19. Shyur, H.J. COTS evaluation using modified TOPSIS and ANP. Appl. Math. Comput. 2006, 177, $251-259$. [CrossRef]

20. Tzeng, G.H.; Chiang, C.H.; Li, C.W. Evaluating intertwined effects in e-learning programs: A novel hybrid MCDM model based on factor analysis and DEMATEL. Expert Syst. Appl. 2007, 32, 1028-1044. [CrossRef]

21. Vitkiene, E. Questions that have to be answered by a well-managed strategy of coastal recreation and tourism enterprises development. TILTAI 2009, 4, 117-124.

22. Wu, W.W. Choosing knowledge management strategies by using a combined ANP and DEMATEL approach. Expert Syst. Appl. 2008, 35, 828-835. [CrossRef]

23. Anton, C.; Gasparotti, C.; Rusu, E. A challenge for the inland navigation-A connection between the Baltic and the Black seas. In Proceedings of the ICTTE Conference, Belgrad, Serbia, 27-28 September 2018.

24. Elomda, B.M.; Hefny, H.A.; Hassan, H.A. An extension of fuzzy decision maps for multi-criteria decision-making. Egypt. Inf. J. 2013, 14, 147-155. [CrossRef]

25. Frynas, J.G.; Mellahi, K. Global Strategic Management; Oxford University Press: New York, NY, USA, 2015.

26. Gray, S.A.; Gray, S.; Cox, L.J.; Henly-Shepard, S. Mental modeler: A fuzzy-logic cognitive mapping modeling tool for adaptive environmental management. In Proceedings of the 46th Hawaii International Conference on System Sciences (HICSS), Wailea, HI, USA, 7-10 January 2013.

27. Healey, N.M. The transition economic of central and eastern Europe: A political, economic, social and technological analysis. Columbia J. World Bus. 1994, 29, 62-70. [CrossRef]

28. Kosko, B. Fuzzy cognitive maps. Int. J. Man-Mach. Stud. 1986, 24, 65-75. [CrossRef]

29. The Burren Programme-Terms and Conditions Tranche 1. Available online: https://www.agriculture.gov.ie /media/migration/farmingschemesandpayments/locallyledschemes/TermsConditionsBurrenSchemeTran cheIV2061016.pdf (accessed on 10 December 2019). 
30. The Burren Life Programme: An Overview Research Series Paper No. 9 March 2016. Available online: http://files.nesc.ie/nesc_research_series/Research_Series_Paper_9_BDunford_Burren.pdf (accessed on 10 December 2019).

31. Galway County Development Plan 2015-2021. Available online: http://www.galway.ie/en/media/GCD P\%202015-2021\%20\%20App\%20II\%20of\%20NIR\%20In\%20Support\%20of\%20the\%20AA.pdf (accessed on 10 December 2019). article distributed under the terms and conditions of the Creative Commons Attribution (CC BY) license (http://creativecommons.org/licenses/by/4.0/). 